hơn ở những đối tượng có $25(\mathrm{OH})$ D dưới 70 $\mathrm{nmol} / \mathrm{L}$ so với trẻ trên $70 \mathrm{nmol} / \mathrm{L}(\mathrm{p}=0,03)$.

Mối liên quan nồng độ 25(OH)D với thời gian nằm viện. Thời gian nằm viện trung bình là $8,3 \pm 2,4$ ngày, ngắn nhất là 5 ngày và lâu nhất là 16 ngày. Trong đó thời gian nằm viện trung bình ở nhóm có nồng độ 25(OH)D < 75 nmol/l là 11,2 \pm 2,8ngày (7 - 16ngày). Thời gian nằm viện của nhóm bệnh nhân có nồng độ $25(\mathrm{OH}) \mathrm{D} \geq 75 \mathrm{nmol} / \mathrm{l}$ là $7,9 \pm 2,0$ ngày $(5-14$ ngày), sự khác biệt có ý nghĩa thống kê với $p=$ 0,002 . Nghiên cứu của chúng tôi gặp 9 bệnh nhân viêm phổi nặng đều có nồng độ $25(\mathrm{OH}) \mathrm{D}$ < 75 nmol/l cân điều trị hỗ trợ hô hấp và sử dụng kháng sinh dài ngày nên việc điêu trị cân thời gian nằm viện cao hơn.

\section{KẾT LUÂ̂N}

Vitamin $D$ có liên quan đến mức độ nặng của viêm phổi. Trẻ ít được bổ sung Vitamin $D$ và có nồng độ $25(\mathrm{OH}) \mathrm{D}$ thấp có nguy cơ bị viêm phổi nặng hởn, có thời gian điều trị kéo dài hơn.

\section{TÀI LIẸU THAM KHẢO}

1. Yakoob MY, et al.(2016). Vitamin D supplementation for preventing infections in children under five years of age. Cochrane
Database of Systematic Reviews. 11),

2. Das RR, et al.(2013). Vitamin d supplementation for the treatment of acute childhood pneumonia: a systematic review. ISRN Pediatr. 2013(459160-.

3. Vũ Thị Hướng (2018). Nghiên cứu nguyên nhân viêm phổi ở trẻ em dưới 5 tuổi tại Khoa Tự Nguyện Bênh Viện Nhi Trung Ương. Luận án văn Thạc sỹ Y học, Trường Đại học Y Hà nội.

4. Lê Văn Tráng (2012). Nghiên cứu tính kháng kháng sinh trong viêm phổi do vi khuẩn ở trẻ em tai bệnh viện Nhi Thanh Hóa. Luận văn bác sỹ chuyển khoà cấp II, Trường Đại học Y Hà Nội.

5. Dinlen $\mathbf{N}$, et al.(2016). Association of vitamin $D$ deficiency with acute lower respiratory tract infections in newborns. The journal of maternalfetal \& neonatal medicine: the official journal of the European Association of Perinatal Medicine, the Federation of Asia and Oceania Perinatal Societies, the International Society of Perinatal Obstet. 29(6), 928-32.

6. Mohamed WA, Al-Shehri MA(2013). Cord blood 25-hydroxyvitamin D levels and the risk of acute lower respiratory tract infection in early childhood. Journal of tropical pediatrics. 59(1), 29-35.

7. McNally JD, et al.(2009). Vitamin D deficiency in young children with severe acute lower respiratory infection. Pediatric pulmonology. 44(10), 981-8.

8. Oduwole AO, et al.(2010). Relationship between vitamin D levels and outcome of pneumonia in children. West African journal of medicine. 29(6), 373-8.

\title{
TÌNH TRẠG DINH DƯỡNG CỦA TRẺ EM MẮC BÊ̂NH RUộT VIÊM TẠI BỆNH VIỆN NHI TRUNG ƯƠNG
}

\section{TÓM TẮT}

Suy dinh dưỡng và chậm phát triển là những biểu hiên chính ngoài đường tiểu hóa trong bênh ruột viêm trẻ em. Mục tiêu: mố tả tình trạng dinh dưỡng của trẻ em mắc bệnh ruột viêm tại bệnh viện Nhi trung ương. Đối tướng và phương pháp: nghiên cứu mô tả loạt ca bệnh gồm 31 trẻ mắc bệnh ruột viêm điều trị tại bênh viên Nhi trung ương từ 01/07/2020 đến 31/03/2021. Kết quả: Tỷ lệ mắc bênh ở trẻ trai và trẻ gái là $1,6: 1$. Tuổi mắc bệnh trung bình là $48,0 \pm 50,3$ tháng. $42 \%$ trẻ suy dinh dưỡng thể thấp còi, trong đó mức đô vừa và năng lần lướt là $19,4 \%$ và $22,6 \%$. $35,5 \%$ trẻ suy dinh dưỡng thể nhẹ cân $(9,7 \%$ nhẹ cân vữa và $25,8 \%$ nhe cân nặng). $25,8 \%$ trẻ có thiếu máu. Tỷ lệ trẻ thiếu calci và thiếu sắt lần lượt là

\footnotetext{
${ }^{1}$ Trường Đại học Y Hà Nọi

²Bênh viện Nhi Trung Ương

Chịu trách nhiệm chính: Nguyễn Thị Việt Hà

Email: vietha@hmu.edu.vn

Ngày nhận bài: 11.5.2021

Ngày phản biện khoa họ: 1.7.2021

Ngày duyệt bài: 12.7.2021
}

\section{Phan Thị Hồng Hải ${ }^{1}$, Nguyễn Thị Việt Hà ${ }^{1,2}$}

$90,3 \%$ và $70 \%$. $34,6 \%$ trẻ có giảm vitamin $D$ và $50 \%$ có thiếu kẽm. Kết luận: Trẻ em mắc bệnh ruột viêm có tỷ lệ suy dinh dưỡng cao trong đó thiếu yểu tố vi lượng là các biểu hiện thường gặp.

\section{SUMMARY}

\section{NUTRITIONAL STATUS IN CHILDREN WITH INFLAMMATORY BOWEL DISEASE AT THE NATIONAL CHILDREN'S HOSPITAL}

Malnutrition and growth retardation are the main extraintestinal manifestations of inflammatory bowel disease in children. Aim: to describe a nutritional status in children with inflammatory bowel disease. Materials and methods: a case series included 31 patients diagnosed inflammatory bowel disease at the National Children's Hospital from July 2020 to March 2021. Results: Morbidity rate of male/female was $1,6: 1$. The mean age at onset of symptoms was 48,0 $\pm 50,3$ months. $42 \%$ children were growth retardation, of which $22,6 \%$ children were severe malnutrition. $35,5 \%$ of children were underweight. Among them, moderate and severe malnutrition was $9,7 \%$ and $25,8 \%$, respectively. Anemia was observed in $25,8 \%$ children. Prevalence of calcium and iron 
deficiency was $90,3 \%$ and $70 \%$, respectively. $34,6 \%$ children were vitamin D insufficient and $50 \%$ children were zinc deficient. Conclusion: Children with inflammatory bowel disease have a high rate of malnutrition, in which micronutrient deficiencies are common.

Keywords: nutrition status, inflammatory bowel disease, children.

\section{I. ĐĂT VẤN ĐỀ}

Bệnh ruôtt viêm là bệnh lý được đặc trưng bởi viêm mãn tính đường tiều hóa với căn nguyên và cơ chế bệnh sinh chưa rõ ràng. ${ }^{1}$ Nếu không được điều trị kịp thời, bệnh nhân bị ruột viêm có thể có các biến chứng cấp tính như loét đường tiêu hóa, tắc ruột, lỗ rò tiêu hóa hay các biến chứng mạn tính như suy dinh dưỡng, chậm phát triển thể chất ${ }^{2}$. Phần lớn nghiên cứu trên thế giới đều tâp trung nghiên cứu các phương pháp điều trị bằng thuốc hoặc can thiệp phẫu thuật trong khi trẻ em là một cơ thể phát triển, cần được chú trọng đánh giá về tình trạng dinh dưỡng, phát triển thể chất và các yếu tố ảnh hưởng đến vấn đề này ${ }^{1,3}$. Kết quả từ một số nghiên cứu tại châu Âu cho thây suy dinh dưỡng và chậm phát triển là những biểu hiện chính ngoài đường tiêu hóa trong bệnh ruột viêm trẻ em. ${ }^{1}$ Các yếu tố liên quan đến suy giảm tăng trưởng trong bệnh ruột viêm bao gồm ăn ít, đi ngoài nhiêu, tăng nhu cầu năng lượng và dinh dưỡng, sử dụng thuốc, mức độ hoạt động của bệnh, nền tảng di truyền và hoạt động thể chất. Tại bệnh viện Nhi trung ương, số lượng trẻ được chẩn đoán và điều trị bệnh ruột viêm có xu hướng ngày càng gia tăng nhưng tình trạng dinh dưỡng của những trẻ em này còn chưa được quan tâm nhiều. Xuất phát từ vấn đề này, chúng tôi tiến hành nghiên cứu với mục tiêu "Mô tả tình trạng dinh dưỡng của trẻ mắc bệnh ruột viêm tại Viện Nhi Trung Ương".

\section{II. ĐỐI TƯợ̂nG VÀ PHƯƠNG PHÁP NGHIÊN CỨU 1. Đối tượng nghiên cứu}

Tiêu chuẩn lựa chọn: 31 trẻ 1 tháng đến 18 tuổi được chẩn đoán xác định bệnh ruột viêm được điêu trị và theo dõi định kì tại Khoa Tiêu hoá, bệnh viện Nhi Trung Ương từ 01/07/2020 đến 31/03/2021. Tất cả các bệnh nhân tuân thủ chế độ điêu trị và tái khám theo định kì ít nhất 3 tháng/lần. Cha mẹ hoặc người chăm sóc trẻ đồng ý tham gia và tuân thủ quy trình nghiên cứu.

Tiêu chuẩn loại trừ: Bệnh nhân mắc các bênh man tính kèm theo như suy tim, bênh thân mạn... ảnh hưởng đến tình trạng dinh dưỡng và sự phát triển thể chất.

2. Phương pháp nghiên cứu: Nghiên cứu cắt ngang mô tả loạt ca bệnh chọn cõ̃ mẫu thuận tiện các bệnh nhân đáp ứng đủ tiêu chuẩn nghiên cứu được đưa vào nghiên cứu. Thu thập số liêu bằng mẫu bênh án nghiên cứu dưa vào phỏng vấn trực tiếp thông tin về tiền sử và bênh sử, khám các triệu chứng lâm sàng và bệnh nhân được làm đẩy đủ xét nghiệm ở thời điểm nghiên cứu.

3. Đạo đức nghiên cứu. Đề cương nghiên cứu đã được thông qua hội đồng đạo đức Bệnh viện Nhi Trung ương (quyết định số 200/BVNTWVNCSKTE). Nghiên cứu này chỉ nhằm mục đích nâng cao hiêu quả khám chữa bênh, ngoài ra không có mục đích nào khác. Các số liệu và thông tin trong nghiên cứu trung thực, chính xác.

\section{KẾT QUẢ NGHIÊN CỨU}

Trong thời gian nghiên cứu từ 01/07/2020 đến 31/03/2021 có 31 trẻ từ 1 tháng đến 13 tuổi được chẩn đoán và điều trị bệnh ruột viêm đủ tiêu chuẩn lựa chọn được đưa vào phân tích

Bảng 1. Đặc điếm chung của trẻ trong nghiên cứu

\begin{tabular}{|c|c|c|c|}
\hline \multicolumn{2}{|c|}{$\begin{array}{c}\text { Đặc điếm chung của đối } \\
\text { tượng nghiên cứu }\end{array}$} & $\mathbf{n}$ & $\mathbf{\%}$ \\
\hline \multirow{2}{*}{ Giới tính } & Nam & 19 & 61,3 \\
\cline { 2 - 4 } & Nữ & 12 & 38,7 \\
\hline \multirow{2}{*}{$\begin{array}{c}\text { Tuổi mắc } \\
\text { bệnh }\end{array}$} & $<2$ tuối & 17 & 54,8 \\
\cline { 2 - 4 } & $2-6$ tuối & 3 & 9,7 \\
\hline \multirow{2}{*}{$\begin{array}{c}\text { Thời gian } \\
\text { điều trị }\end{array}$} & $>6$ thối & 11 & 35,5 \\
\cline { 2 - 4 } & $<6$ tháng & 8 & 25,8 \\
\hline \multirow{2}{*}{ Thể bệnh } & 23 & 74,2 \\
\cline { 2 - 4 } & $\begin{array}{c}\text { Crohn } \\
\text { Viêm đại tràng } \\
\text { chảy máu }\end{array}$ & 28 & 90,3 \\
\hline
\end{tabular}

Nhận xét: Trẻ trai mắc bệnh nhiều hơn trẻ gái, tỷ lệ trai/gái là $1,6: 1$. Tuổi trung bình mắc bệnh của trẻ là $48 \pm 50,3$ tháng ( 1 tháng -13 tuổi), trong đó $54,8 \%$ khởi phát bênh trước 2 tuổi. 74,2\% trẻ đã được điều trị trên 6 tháng. 90,3\% trẻ được chẩn đoán bênh Crohn.

Bảng 2: Tình trạng dịnh dưỡng của trẻ trong nghiên cứu

\begin{tabular}{|c|c|c|c|c|c|c|}
\hline Tình trăng & \multicolumn{2}{|c|}{ Thấp còi } & \multicolumn{2}{|c|}{ Nhẹ cân } & \multicolumn{2}{|c|}{ Gây còm } \\
dinh dướng & $\mathbf{n}$ & $\%$ & $\mathbf{n}$ & $\%$ & $\mathbf{n}$ & $\mathbf{\%}$ \\
\hline $\begin{array}{c}\text { Không suy } \\
\text { dinh dương }\end{array}$ & 18 & 58,1 & 20 & 64,5 & 22 & 71,0 \\
\hline $\begin{array}{c}\text { Suy dinh } \\
\text { dương vữa }\end{array}$ & 6 & 19,4 & 3 & 9,7 & 7 & 22,6 \\
\hline $\begin{array}{c}\text { Suy dinh } \\
\text { dương nặng }\end{array}$ & 7 & 22,6 & 8 & 25,8 & 2 & 6,4 \\
\hline
\end{tabular}

Nhận xét: $42 \%$ trẻ có tình trạng suy dinh dưỡng thể thấp còi, trong đó $19,4 \%$ suy dinh dưỡng vừa và $22,6 \%$ suy dinh dưỡng nặng. 35,5\% bệnh nhân suy dinh dưỡng thể nhẹ cân 
trong đó $9,7 \%$ mức đô vừa và $25,8 \%$ mức độ nặng. 29\% trẻ suy dinh dưỡng thể gây còm.

Bảng 3: Đặc điểm huyêt học của trẻ bi bệnh ruột viêm

\begin{tabular}{|c|c|c|c|}
\hline \multicolumn{2}{|c|}{$\begin{array}{l}\text { Thay đối chỉ số huyết học } \\
\text { của trẻ bị bệnh ruột viềm }\end{array}$} & & $\%$ \\
\hline \multirow{4}{*}{$\begin{array}{c}\text { Thay } \\
\text { đổi } \\
\text { hồng } \\
\text { câuu } \\
\end{array}$} & Số lượng hồng cầu giảm & 1 & 3,2 \\
\hline & Hemoglobin giảm & 8 & 25,8 \\
\hline & $\mathrm{MCV}<80 \mathrm{fl}$ & 18 & 58,1 \\
\hline & $\mathrm{MCH}<28 \mathrm{pg}$ & 20 & 64,5 \\
\hline \multirow{3}{*}{$\begin{array}{l}\text { Thay đổi } \\
\text { bạch cầu }\end{array}$} & Bạch câu tằng & 11 & 35,5 \\
\hline & Bạch cầu trung tính tăng & 9 & 29,0 \\
\hline & Bạch câu ưa acid tăng & 2 & 6,5 \\
\hline \multirow{2}{*}{\multicolumn{2}{|c|}{ Số lượng tiếu câu tăng }} & 12 & 38,7 \\
\hline & & 7 & 22,6 \\
\hline
\end{tabular}

Nhân xét: $25,8 \%$ bệnh nhi có hemoglobin giảm so với tuổi. Tỷ lệ trẻ bi ruột viêm có $M C V$ giảm dưới $80 f 1$ và $\mathrm{MCH}$ dưới $28 \mathrm{pg}$ lần lượt là $58,1 \%$ và $64,5 \%$. $35,5 \%$ trẻ có tăng số lượng bạch cầu trong đó $29 \%$ tăng bạch cầu trung tính và $6,5 \%$ tăng bạch cầu ưa acid. 38,7\% bệnh nhân có tăng tiểu cầu $>400 \mathrm{G} / \mathrm{L}$ và $22,6 \%$ trẻ có tốc độ máu lắng tăng.

Bảng 4: Tình trang thiếu vi chất dinh dưỡng ở trẻ mắc bệnh ruột viêm

\begin{tabular}{|c|c|c|c|}
\hline \multirow{2}{*}{ Vi chất } & \multicolumn{2}{|c|}{ Thiếu vi chất } & \multirow{2}{*}{$\begin{array}{c}\text { Trung } \\
\text { bình } \pm \\
\text { SD }\end{array}$} \\
\hline & $n / N$ & $\%$ & \\
\hline $\begin{array}{l}\text { Calci toàn phần } \\
\text { giảm }\end{array}$ & $12 / 31$ & 38,7 & $2,4 \pm 0,2$ \\
\hline Calci ion giảm & $28 / 31$ & 90,3 & $1,0 \pm 0,1$ \\
\hline $\begin{array}{l}\text { Phosphataza } \\
\text { kiềm giảm }\end{array}$ & $1 / 31$ & 3,2 & $\begin{array}{c}203,9 \pm \\
71,7\end{array}$ \\
\hline Magie giảm & $1 / 28$ & 3,6 & $0,9 \pm 0,1$ \\
\hline $\begin{array}{l}\text { Sắt huyết thanh } \\
\text { giảm }\end{array}$ & $19 / 27$ & 70,4 & $7,0 \pm 5,4$ \\
\hline Ferritin tăng & $6 / 29$ & 20,7 & $\begin{array}{c}95,9 \pm \\
92,7\end{array}$ \\
\hline Phospho giảm & $3 / 27$ & 11,1 & $1,5 \pm 0,2$ \\
\hline Kẽm giảm & $12 / 24$ & 50,0 & $10,7 \pm 4,4$ \\
\hline Vitamin D giảm & $9 / 26$ & 34,6 & $\begin{array}{c}79,2 \pm \\
50,9\end{array}$ \\
\hline
\end{tabular}

Nhận xét: Tỷ lệ trẻ mắc bệnh ruột viêm thiếu calci và thiếu sắt lần lượt là $90,3 \%$ và $70 \%$. 20,7\% tăng ferritin huyết thanh. 34,6\% trẻ có giảm vitamin $\mathrm{D}$, trong đó có $11,5 \%$ trẻ có nồng độ vitamin $\mathrm{D}$ dưới $30 \mathrm{nmol} / \mathrm{L}$. Tỷ lệ trẻ thiếu magie, phospho và kẽm lần lượt là 3,6\%; $11,1 \%$ và $50 \%$.

\section{BÀN LUÂNN}

Nghiên cứu được tiến hành trên 31 trẻ được chẩn đoán mắc bệnh ruột viêm, trong đó $61,3 \%$ là trẻ trai (bảng 1), tỷ lệ trẻ trai/gái trong nghiên cứu là 1,6:1. Tỷ lệ này cao hơn so với nghiên cứu của Selbuz năm 2020 (52,8\% trẻ trai). ${ }^{1}$ Trong nghiên cứu của chúng tôi, tuổi khởi phát triệu chứng trung bình là 48 tháng, tuổi chẩn đoán là 57 tháng tuổi, sớm hơn rất nhiều so với nghiên cứu của Selbuz (12,9 tuổi $)^{1}$. Đa phần các bệnh nhân trong nghiên cứu của chúng tôi đều đã điều trị và theo dõi lâu dài tại bệnh viện (74,2\% điều trị trên 6 tháng). Các bệnh nhẩn nghiên cứu đa phần là bệnh nhân Crohn $(90,3 \%)$.

Tất cả trẻ mắc bệnh ruột viêm được đánh giá tình trạng dinh dưỡng qua các chỉ số nhân trắc cân nặng, chiều cao (bảng 2). Dựa trên chỉ số chiều cao theo tuổi, $42 \%$ trẻ suy dinh dương thể thấp còi, cao hơn trong nghiên cứu của Selbuz và cộng sự (5,6\%) và Aurangzeb 2011 (3,6\%). . $^{1,3}$ Tỷ lệ trẻ bị bệnh ruột viêm suy dinh dưỡng thế nhẹ cân trong nghiên cứu của chúng tôi là $35,5 \%$, cao hơn so với các nghiên cứu khác (11,6\% trong nghiên cứu của Selbuz 2020, 3,6\% trong nghiên cứu của Aurangzeb 2011). ${ }^{1,3}$ Sự khác biệt này có thể là do bệnh ruột viêm là một bệnh lý viêm mạn tính của đường tiêu hóa nên trẻ em mắc bệnh có thể bị ảnh hưởng cả cân nặng và chiều cao trong thời gian dài. Kết quả này tương đồng với kết quả về tình trạng dinh dưỡng của trẻ mắc bệnh ruột viêm tại thời điểm chẩn đoán của Nguyễn Thị Ngọc Hồng ${ }^{4}$. Điêu này có thể do trong điều kiện Việt Nam hiện nay, các phương pháp can thiệp dinh dưỡng trong điều trị bệnh lý ruột viêm còn chưa được quan tâm nhiều do hạn chế về phương tiên và kiến thức khiến tỷ lệ trẻ mắc bệnh ruột viêm bị suy dinh dưỡng vẫn còn cao dù là mới chẩn đoán hay đã điều trị một thời gian. Nguyên nhân suy dinh dưỡng ở trẻ mắc bệnh ruột viêm có thể do giảm lượng thức ăn, kém hấp thu do tổn thương niêm mạc ruột, ức chế tăng trưởng do tăng phản ứng viểm, hoặc do tác dụng của điều trị (corticoids) lên tình trạng dinh dươnng ${ }^{1}$.

Kết quả từ bảng 3 cho thấy tỷ lệ trẻ có giảm hemoglobin so với tuổi là $25,8 \%$, tương tự nhu nghiên cứu của Aljomah 2018 (20,51\%), nhưng tỷ lệ này thấp hơn tỷ lệ thiếu máu tại thời điểm chẩn đoán theo nghiển cứu của Ṅguyễn Thị Ngọc Hồng $(69,8 \%)$, hay của Aljiomah 2018 $(67,3 \%){ }^{4,5}$ Như vậy, trong quá trình điêu trị trẻ bị bệnh ruột viêm cũng giảm tình trạng thiếu máu so với lúc mới chẩn đoán. Về các chỉ số liên quan đến tình trạng viêm, tỷ lệ trẻ có bạch cầu tăng so với tuổi, tăng bạch cầu ưa acid, tốc độ máu lắng tăng lần lượt là $35,5 \%, 6,5 \%$ và $22,6 \%$, giảm so với nghiên cứu của Nguyễn Thị 
Ngọc Hồng $(25,6 \%, 6,5 \%$ và 48,7\%) 4 . Sự khác biệt này có thể giải thích do hiệu quả của quá trình điêu trị bệnh ruột viêm giúp làm giảm tình trạng viêm, giảm mức độ hoạt động bệnh.

Trẻ bị bệnh ruột viêm thường có tình trạng suy dinh dưỡng và thiếu yếu tố vi lượng. Thiếu calci, sắt và kẽm là biểu hiện thường gặp nhất trong nghiên cứu của chúng tôi (Bảng 4). Tỷ lệ trẻ thiếu calci trong nghiên cứu của chúng tôi là $90 \%$ cao hơn nhiêu so với nghiên cứu của Massironi và cộng sự (13\% ở Crohn, $10 \%$ ở viêm loét đại trực tràng chảy máu). ${ }^{6}$ Trẻ mắc bệnh ruột viêm bị giảm calci huyết thanh có thể do tổn thương ruột non, tác dụng phụ của thuốc corticoids hoặc bổ sung không đủ. Tỷ lệ trẻ giảm vitamin $\mathrm{D}$ trong nghiên cứu của chúng tôi $(<50$ $\mathrm{nmol} / \mathrm{L})$ là $34,6 \%$, và thiếu vitamin $\mathrm{D}(<30$ $\mathrm{nmol} / \mathrm{L})$ là $11,5 \%$. Kết quả này cao hơn so với nghiên cứu của Levin $(19,2 \%$ và $3,8 \%)$, nhưng thấp hơn nghiên cứu của Laasko $(51 \%$ và $30 \%){ }^{7}$ Điều này có thể do trong quá trình điều trị cũng như hạn chế các tác dụng không mong muốn của thuốc, các bác sĩ chuyên khoa tiêu hóa đã chú ý bổ sung vitamin $D$ đường uống cho trẻ. Tuy nhiên tình trạng thiếu vitamin $D$ vần cao có thể do mức độ bệnh ảnh hưởng đến hấp thu vitamin $\mathrm{D}$, hoặc liều lượng hoặc thời gian bổ sung không đủ, cho thấy cần có các biện pháp tích cực hơn trong điều trị và phòng ngừa thiếu vitamin D. $70 \%$ trẻ có sắt huyết thanh trong nghiên cứu của chúng tôi giảm, tương đồng với kết quả nghiên cứu của Song và công sự (72\%), Wiskin và cộng sự $(70 \%$ Crohn, $65 \%$ viêm loét đại trực tràng chảy máu). ${ }^{2,8}$ Các yếu tố gây thiếu sắt ở bệnh nhân ruột viêm có thể do mức độ hoạt động bệnh, lượng ăn vào kém, bổ sung khổng đầy đủ. Kết quả nghiên cứu của chúng tôi cho thây tình trạng thiếu sắt có thể vẫn tiếp diễn dù đã được bổ sung bằng đường uống trong quá trình điều trị bệnh. Dù tỷ lệ thiếu sắt huyết thanh cao nhưng ferritin không giảm có thể do hoạt động viêm gây tăng nồng độ ferritin huyết thanh. Trong nghiên cứu của chúng tôi tỷ lệ trẻ thiếu magie chỉ chiếm 3,6\%, nhỏ hơn so với tỷ lệ thiếu magie ở người lớn mắc bệnh (13-88\%). Các dữ liệu về tỷ lệ thiếu magie ở trẻ mắc bệnh ruột viêm còn rất hạn chế. Tỷ lệ trẻ thiếu phospho là $11 \%$. Các nghiên cứu về phospho trong bệnh ruột viêm ở trẻ em còn ít, nguyên nhân thiếu phospho có thể do tổn thương tại ruột non, hoặc do các thuốc bổ sung sắt trong điều trị. Trẻ bệnh ruột viêm có tỷ lệ thiếu kẽm lên đến $50 \%$ trong nghiên cứu của chúng tôi, kết quả này tương tự với nghiên cứu của Song $(51 \%)^{2}$ và cao hơn hầu hết kết quả nghiên cứu khác như Alkhouri (40\%), Ehrlich (31\%). ${ }^{7,9}$ Trẻ mắc bệnh ruột viêm có nguy cơ thiếu kẽm có thể do giảm lượng ăn vào hoặc kẽm hấp thu. Hơn nữa tiêu chảy (triệu chứng thường gặp của bệnh ruột viêm) làm tăng bài tiết kẽm và làm giảm lượng kẽm toàn cơ thể.

\section{KẾT LUẬN}

Trẻ em mắc bệnh ruột viêm có tỷ lệ suy dinh dưỡng cao. Tình trạng suy dinh dưỡng dẫn đến thiếu các yếu tố vi lượng sắt, calci - vitamin $D$ và kẽm. Đây là biểu hiện thường gặp nhất ở trẻ mắc bệnh ruột viêm nên cần chú ý can thiệp dinh dưỡng, theo dõi định kì và bổ sung vi chất cần thiết trong quá trình điều trị.

\section{TÀI LIÊU THAM KHẢO}

1. Selbuz $S$, Kansu A, Berberoğlu $M$ et al (2020). Nutritional status and body composition in children with inflammatory bowel disease: a prospective, controlled, and longitudinal study. Eur ] Clin Nutr. Published January 9, 2020. doi:10.1038/s41430-019-0555-1

2. Song SM, Kim Y, Oh SH et al (2014). Nutritional Status and Growth in Korean Children with Crohn's Disease: A Single-Center Study. Gut Liver. 2014;8(5):500-507. doi:10.5009/gnl13183

3. Aurangzeb B, Leach ST, Lemberg DA et al (2011). Assessment of Nutritional Status and Serum Leptin in Children With Inflammatory Bowel Disease. J Pediatr Gastroenterol Nutr 52: 536-541. doi:10.1097/MPG.0b013e3181f87a955

4. Nguyễn Thị Ngọc Hông, Nguyễn Thị Việt Hà (2020). Đặc điểm lâm sàng và tổn thương trên nội soi của trẻ bị bệnh ruột viêm tại bệnh viện Nhi trung ương. Tạp chí Nighiên cứu Y học, 128(4), 58-68.

5. Aljomah G, Baker SS, Schmidt $K$, et al (2018). Anemia in Pediatric Inflammatory Bowel Disease. J Pediatr Gastroenterol Nutr. 2018;67 (3):351-355. doi:10.1097/MPG.0000000000002002

6. Massironi S, Rossi RE, Cavalcoli FA, et al (2013). Nutritional deficiencies in inflammatory bowel disease: therapeutic approaches. Clin Nutr Edinb Scotl. 2013;32(6):904-910. doi:10.1016/ j.clnu.2013.03.020

7. Fritz J, Walia C, Elkadri A, et al (2019). A Systematic Review of Micronutrient Deficiencies in Pediatric Inflammatory Bowel Disease. Inflamm Bowel Dis. 2019;25(3):445-459. doi:10.1093/ ibd/izy271

8. Wiskin AE, Fleming BJ, Wootton SA, et al (2012). Anaemia and iron deficiency in children with inflammatory bowel disease. J Crohns Colitis. 2012;6(6):687-691. doi:10.1016/j.crohns.2011.12.001

9. Alkhouri RH, Hashmi $H$, Baker RD, et al (2013). Vitamin and Mineral Status in Patients With Inflammatory Bowel Disease. J Pediatr Gastroenterol Nutr. 2013;56(1):89-92. doi:10.1097/MPG.0b013e31826a105d 